\title{
Psychological Impact of Social Transition to Albanians after Year 1990
}

\author{
Arbjola Halimi, PhD Cand. \\ University of Elbasan "Alexander Xhuvani", Faculty of education, Psychology Department \\ Email: arbjola_h@yahoo.com
}

\section{Doi:10.5901/ajis.2015.v4n1s2p27}

\section{Abstract}

Many psychological transition theories argue that there is a very strong connection between life span events and social events were individual spent their life. Some of these social changes are considered also conditions for individual changes to happen or not in a healthy way. In this study we try to gain some evidence about the nature and impact that social change has to individual changes that comes to an individual life span. Population on focus are Albanians during time of their social transition after communism, so after year 1990. Methods and instruments used to gain the data on this retrospective research are selfreport, standard questionnaires and also paper and journals reviews. Individuals are Albanian people 40 years old at least. Analyses are made by a descriptive statistic. Findings shows that there is a strong and significant correlation between social changes such as political, economical and others (ex. emigration, migration) and individual changes in Albanian people during this time. Negative social changes such as increased crime or bad services on health, go to more distress and dysfunction in individual life span and transition. The article suggests that a better understanding of this interference and impact will allow better politics and care in both individual and social level.

Keywords: individual, transition, social, psychological impact, well-being

\section{Introduction}

Transition theories ${ }^{1}$ and authors such as Hopson, Sugarmen, Schlossberg, etc suggests that transition is the primary cause of distress and threaters of personal psychological well-being. They argue that during their life span individuals survive many changes and events in their live in a personal and social level which can cause them from happiness to a great level of distress due to their impact on a person's life and his inner processes. That means that personal ${ }^{2}$ and social transition go narrowly together and they both affect psychological or emotional well-being. Of course they admit that there are differences in the level of distress that transitional features and phases can cause to individuals, varying by their sources ( economical, health care, emotional security) and coping strategies (perception of risk, etc). This transition takes often a cycle from positive and negative events but as we can understand if events that occur are mostly negative and if this is combined by negative social factors such as those related will low level of economy, education, social and health, personal psychological well-being of a person is well threaded.

\section{Method}

Principal method used to gain the data is survey and main Instrument is a Self-Experiences Questionaire. People are asked for the kind of experience they have in their lives during transition time and their emotional impact. Data collected are compared with other data for social changes that occurred during this time. This data are gained from 2001 CENSUS (Population and Residence Registration Rapport) in Albania, on e research view perspective.

Simple for the questionaire is about 120 Albanian people, living in Albania during the time, not less than 40 years old. Data calculation and analyze is made by using SSPS and prescriptive statistic.

1 Dai Williams, 1999

2 John Fisher, 1999, 2012 


\section{Discussion and Results}

Albania, a post-communist country as is known, has a long social transition in all levels and dimensions. Data collected from the census 2001 give as e realistic view of what happened during this time in Albania.

According to INSTAT report for Population and Residence Registration of year 2001, which is also a survey of living conditions and disparity, in Albania after year 1990 despite some positive changes during this transition period of time, there is also good evidence that shows sensitive disparities in the living level, especially in village zones. Levels of unemployment are really increased specially during crises period such as year 1993 where the level were 29,0\%. In Year 2003 this level were 22, 7\%, the highest in the region and some cities goes to 40\%. There are also a lot of differences in human development level from one area to another (city and village, city and city) were principal obstacle for reform development and improvement of social problems is political instability and uncertainty of Albanian people although this is very difficult to verify from this data.

Health care and sanity before year 1990 has been characterized by a high level of infant mortality and mother mortality. This is most evident in some cities than in others and seems to be related not much more with the level of poverty than with the inequalities in education, specially the women.

Peculiarity of this period of time is the sending of medical personal in deepest and fares zones of the country. During 1990 and after medical and health care inherited a very week infrastructure for medical care and service. Many of these services need recovery, tools, professional personnel and infrastructure.

In the period of time before years ' 90 in Albania $90 \%$ of school children finished the primary school forced cycle, $74 \%$ the second cycle (middle school) and 40\% of them follow university (1972 report). Despite these global tendencies, there are many differences based on demography where north cities are statistically lower than the average percent in education, in comparison with cities of south Albania which are higher than average. These differences as citied in report has been created by the general lack or low level of urbanization, tradition influences, religion and age structure of mountains zones(north cities). Tendencies to miss illiteracy even high, miss the lack of quality in education by overpopulation of class rooms, lack of environments and school material, >ensure, limits, the principle of "supporting in your own force which provide isolation in Albania from the outside world and lack of personal freedom, causing so the missing of specialists and efficacy literature.

Rapid Changes that happened in Albania during and after the year 1990 with their political, economical and social nature caused deterioration especially at the beginning of these years. Some of these problematic include teaching \& teacher quality, abandon of school, several of physical buildings conditions, warm, lighting, environments, lack of teachers with adequate education and profilisation which increased more disparities of educational conditions between villages and cities and that caused other consequences even in the future.

In relation with life, building and casemate conditions in Albania, they has been inappropriate before and after "90ins. In 1970 there were build in Albania 185.000 apartments or 7.400 buildings in year two effort devastating previous conditions. These efforts did not fulfill shelter needs increased with population number growth. Services and facilities remain the same. At the end of ' 80 more than half of village population did not have drinking water and more several conditions to the warm. By the middle of ' 90 disparities for these conditions between village and city still existed. Cities were better but to the villages these conditions were still very inappropriate. All around Albania at the time were overpopulation in buildings were the mostly of these building has two rooms and a kitchen. More than two-thirds of these buildings were overpopulated even in year 2001 with an exception of principal cities such as Tirana and Durres.

Poverty level evaluations made by World Bank and INSTAT (2003) are 3.047 lek for person in food level and 4.891 lek for full poverty level. This evidence show that more than $25.4 \%$ of Albanians live under the level of full poverty (780.000 of them). This number constitutes one quarter of Albanian population during the time and is similar to that of central Asia, even higher in comparison with other countries of Southeast Europe ${ }^{3}$

Primarily this level is referred to the level of full poverty, as for the food level there are $4.7 \%$ of them. (WB and INSTAT 2003).

Mostly of poverty population lives on the village ( $46 \%$ in mountainous area) due even to the migratory movements from these areas toward more urban areas.

Back to our research when people are asked for their personal experiences and the emotional impact that those events has had in their lives in post-communist Albania, their illustrate several events which by their content are well

${ }^{3}$ INSTAT, 2001 
related with social, economical and political factors described above. Some of these events include: standing to jail, changes in eating and sleeping habits, changes on work (position, job, conditions,etc), loosing job, illness or severe accidents of a related or friend, severe changes in financial status, changes residence, illness or personal impairment, borrows, property problems, school abandon, big changes in life conditions, big changes in social activities, lack of contact with family (emigrants), adjustment difficulties( by migration), daily frustration, raised crime in their area of their living. People are asked for different years from year 1985 to year 2013. Evidences shows that some of this experience are not much different in occurrence tendency from 1985 and after 1990(the big revolution), such as problems with financial status, daily frustration (mostly argued by their fear to speak and think in a free way and the doubts from the surroundings, the spiunazh).

The other experiences are typical after year 1990. It is important to underline that these experienced are matched even for their emotional impact of individuals experiencing them. According to the data collected the evidences before year 1990 shows a more stability in negative emotional level when the more chosen alternative is -2 (middle negative emotional impact) and more wide spread occurrence of this experience. Unlike this during and after year 1990 there is a widespread of more negative and positive experiences which differ in their intensity from -3 (extremely negative emotional impact) to +2 (middle positive emotional impact). It is also noted that this intensity level is not as linear as before this year but is much more changeable from a person to another (people choosing this may be smaller but the intensity of emotional impact chosen is higher). So the evidence shows a split on population related to the negative and positive experience and the emotional impact that they have proved about. Because the instrument also measure economical level these data shows that those people having more bad and negative personal experiences have or had a low economical level (after year 1990). This instrument is aplyed to subjects that already have 40 years old or more and and data shows dhe second prescription of emotional impact level above is more evident from age 40 to 48 than to olders one. Asked for their live transition experience they agree that it has been more difficulty in challenging them during the years 1991,1992, 1993, 1997, 1998, 2006, 2007, and now. According to data, statistics on security ${ }^{4}$, there is a strong correlation between increased crimininality to this years and the difficulties that people had in their personal transitional experiences such as marriage, children and family, find a job, etc.

We suggests that a better understanding would be held if people are asked in a autobiographical view which can be provided in others researches.

\section{References}

Dai, Williams (1999). British Psychological Society Occupatonal Psychology Conference, January. INSTAT, (2001), Census for population and building registration, report publication in 2003. Albania State police general directory archive, 2010

wwwbusiness.com. John Fisher personal transition curve and personal change, Tenth International Personal Construct Congress, Berlin, 1999, revised 2012 Leicester University, England. 
